\title{
Determinant of Small and Medium Enterprises (SMEs) Low Participation in Public Procurement in Lagos, Nigeria
}

\author{
Solomon Bamidele Olusegun ${ }^{1 *} \quad$ James Olalekan Akinbode $^{2}$ \\ 1.Procurement unit, University of Lagos, Akoka Nigeria \\ 2.Department of Business Administration, The Federal Polytechnic Offa, Kwara State Nigeria
}

\begin{abstract}
It is an established fact that Small and Medium Enterprises (SMEs) are crucial to economic development of any nation. SMEs participation in every sphere of economic activities including public procurement is one of the ways the sector can promote economic development of the country. However, SMEs sometimes are usually reluctant to sell to government. This study identified and classified into eight themes factors responsible for the low participation of SMEs in public procurement in Lagos State, Nigeria. Data were collected with questionnaires from 193 SMEs Chief executives. Data generated were analyzed using ranking method. The study revealed that perceived lack of transparency in public procurement proceedings, disproportionate eligibility criteria and burdensome nature of public procurement are the major reasons SMEs are reluctant to participate in public procurement in Lagos, Nigeria. It was concluded that transparency is vital in public procurement for SMEs to adequately participate in the process. The study recommended that in order to boost SMEs participation in public procurement transparent procurement management must be guaranteed.
\end{abstract}

Keywords: Determinant; SMEs; Public procurement; Contract; Eligibility criteria.

\section{Introduction}

There have been global advocacy for the development of strong SMEs in countries around the world especially the developing countries due to the important roles they can play in the economic growth of a nation. SMEs play pivot role through several pathways that go beyond job creation which has been well discussed. They are growth-supporting sector that not only contribute significantly to improve living standards, but also bring substantial local capital formation, drive innovations and promote competitions in developing economies. A collaborative survey conducted by the Small and Medium Enterprises Development Agency of Nigeria (SMEDAN) and National Bureau of Statistic (NBS) in 2013 revealed that MSMEs sector as at 2013 employed $59,741,211$ representing $84.02 \%$ of the total labour force in Nigeria while its contribution to the Nation's Gross Domestic Product (GDP) stood at $48.47 \%$. Similarly, World Bank (2003) estimates suggest that SMEs in People's Republic of China (PRC) account for $99.9 \%$ of the total number of businesses employ $84 \%$ of the nation's workforce and account for $71 \%$ of total sales. In Europe, SMEs is said to be the major source of entrepreneurial skills, innovation and employment and account for provision of about 75 million jobs (Pephrah, Mensah, Akosah, 2016).

Despite the important roles play by the sector, research has shown that it has continued to experience many constraints that have hampered its growth and the realization of its full potential. SMEDAN and NBS in their survey (2013) identified the main challenges confronting the improved operations of SMEs in Nigeria to be access to finance, poor infrastructure, inconsistency in government policies, poor support, access to market, multiple taxation and obsolete technology. In the same vein, Chima (2016) attributed poor growth of SMEs in Nigeria to problems of competition, taxes, marketing and finance.

In an attempt to encourage growth of SMEs, many countries of the world have embarked on several policies. Among such policies is opening of public procurement market to SMEs. Public procurement is acquisition of goods, works and services using public funds (World Bank, 1995). It involves the process of soliciting for tenders, submission and collection of bids, evaluations of bids received, award of contract and contract implementation. The process is often competitive and very challenging to SMEs when compared to their large enterprises for a number of reasons such as capital requirement, technical know-how, etc. For instance in Nigeria, Small Enterprises are those enterprises whose total assets (excluding land and building) are above Five Million Naira but not exceeding Fifty Million Naira with a total workforce of above ten, but not exceeding fortynine employees (SMEDAN, 2013). With this description of what small enterprises are in Nigeria, it will be difficult for them to compete favorably with large firms in public procurements.

To avert the tendencies of SMEs exclusion from public procurements, policies of 'set aside' and 'quotas' were put in place in some countries such as Canada, South Africa, India, etc. Although Nigeria is not left out, effort at encouraging SMEs participation in public procurement has been pushed for by government. Akenroye and Aju (2013) revealed that the Local Content policy of Nigeria was put in place as a way of encouraging oil and gas companies to procure from SMEs in local communities. Tumkella (2003) reported that much could not be achieved despite the efforts of the government due to abuses, poor project evaluation and corruption. This claim was buttressed by Ihua (2010) when he adduced that the Local Content policy of the 
government led to increase in contract awards to the large firms as opposed to the intended higher SMEs participation.

The need for SMEs to avail themselves the opportunities provided by Public procurement cannot be overemphasized. Fee, Erridge and Hennigan (2002) cited in Flynn and Davis (2006) revealed that public procurement presents stable and predictable sources of demand while Loader (2005) and MacManus (1991) surmised that public procurement come with near certainty of payment. Studies have also established a mutually beneficial relationship between SMEs and Public procurement. Zheng, Walker and Harland (2006) averred that there are various economic benefits to be derived when government buys from SMEs. This position was buttressed by Ebig and Ghas (2016) when they averred that considering SMEs in Public procurement can lead to a number of economic advantages such as higher innovation rate. This is because SMEs are able to adapt and change quickly and tend to be closer to their customers (Peprah, Mensah, \&Akosah, 2016).

Despite the proven benefits inherent in SMEs participation in public contract, there is a growing rate of apathy on the part of the SMEs in public procurement participation. Flynn and Davis (2016) revealed that "while it may be mutually beneficial for SMEs and public sector organizations to do business, the reality of everyday procurement presents a less sanguine picture”. Loader (2005) and MacManus (1991) as cited in Flynn and Davis, (2016) observed that SMEs have consistently expressed their dissatisfaction with public sector tendering process and procedures (Purchase, Goh \& Dooley, 2009). This view was re-echoed by Afande (2015), who averred that many potential suppliers, including small and micro firms, may be discouraged from tendering for public sector contracts because of a number of perceived or real barriers which include: information hoarding about opportunities(including subcontracting opportunities); a belief that the processes involved in bidding are unnecessarily complex and costly; not understanding the requirements fully; even if they do bid, SMEs do not always get through the initial selection stage, etc. Similarly, Macpherson and Holt (2007) surmised that lack of skills for preparing good bids, cost of tendering and excessive documentation requirements are factors dissuading SMEs from participating in public procurement. Morrisey and Pittaway (2006) averred that delayed payment and disproportionate qualification criteria are some of the factors that prevent SMEs participation in public contract. Nkonge (2013) revealed that ethical aspect hinders the SMEs from participating in tendering due to in-transparency in the process.

Akenroye and Aju (2013) in their study of barriers to SMEs participation in public procurement in Nigeria using the Federal Capital Territory Abuja as a case-study revealed that information obscurity and incapability are the most foremost barriers facing SMEs participation in public procurement. In his account Huka (2016) reported that while studying the contribution of public procurement to the success of SME in Moshi Municipality in Tanzania observed that low winning rate of SME in public procurement is due to unfavorable technical conditions, unfavorable financial conditions as well as unfair evaluation criteria. In another related study carried out by Obanda (2011), it was revealed that SMEs are often excluded from public procurement contracts because of administrative requirements for mandatory bidding processes and their inadequate size and capacity to deliver. Another view established for the reason why SMEs struggle with public procurement in the opinion of Loader (2005) were unfamiliarity and not always efficient marketplace, bureaucratic tendering procedures and their inherent resource limitations while Georghious, Edler and Uyarra (2014) identified low professionalism and high-risk aversion as factors affecting SMEs participation in public procurement.

Admittedly, many studies have revealed factors hindering SMEs access to public market but to the best of our knowledge, no published article has ranked these factors in order of impact especially in Lagos, Nigeria. Lagos State is the commercial nerve center of Nigeria and according to SMEDAN (2013) is the State with the highest number of SMEs in Nigeria. This study therefore identified and classified factors discouraging SMEs from participating in public procurement with the intention of ranking them in order of effect.

\section{Method}

A survey of SMEs Chief executives / Managers in Lagos, Nigeria was conducted between July and September, 2016 to investigate the factors discouraging their SMEs participation in Public contract. Several factors affecting SMEs participation in public contract have been identified in literature. These factors were then re-phrased and expended into 8 statements. These factors were: Disproportionate eligibility criteria, bias evaluation/award criteria, multiple tax deduction, late / unfavorable payment terms, lack of transparency, Unethical behaviour, burdensome nature of procurement and complex contract management.

The questionnaire was broadly divided into the following sections: Section A covers personal information about the respondents' gender, years in business, educational qualification, etc. Section B covers information on the respondent's participation in public contracts and factors affecting their participation. The respondents were asked to rank their agreement with the statement of factors that discourage them from participating in public contract based on a five point Likert scale. The five Likert scale was adopted because it provides unambiguous results and ease of usage (Ekanayake \& Ofori, 2004). 300 questionnaires were administered on Chief executives/ managers of some SMEs in Lagos State who were purposively selected. Out 
of the 300 questionnaires administered, 211 were retrieved while 18 questionnaires out of the 211 questionnaires were invalid due to error of partial completion. Thus, 193 valid questionnaires were used for the analysis representing $70.3 \%$.

In the study, Cronbach's coefficient alpha was calculated to ascertain the reliability of the five -point scale which has been used in the survey. The reliability test measures the internal consistency among the factor discouraging SMEs participation in public contract. The reliability test of the 8 factors was 0.78 . According to George and Mallery (2003), a coefficient of 0.7 and above is considered adequate.

\section{Results and Discussions}

\subsection{Profile of the Respondents}

Responses to questions on the profile of the respondents in terms of their gender, level of education, years in business, nature of business were presented in Table I. From the responses, it can be deduced that there were more male respondents than the female within the study area. Specifically $67.9 \%$ (131) of the respondents were male and $32.1 \%$ (62) females. This gives an indication that SMEs in the study area is male dominated. This disparity is expected because of the dwindling nature of business in Nigeria. It requires bravery and the emotional tenacity to carry on even against all odds. The result of the analysis of the respondents' level of education revealed that $1.6 \%(3)$ holds $\mathrm{PhD}$ certificate, 30\% (58) were Masters degree holders, $65.3 \%(126)$ hold BSc/HND and 3.1\%(6) hold Diploma/Certificate. This shows that the respondents were literate and this accounted for proper understanding of the issue under discussion. Responses to question on years of business existence revealed that $21.2 \%(41)$ of the respondents have been in business for less than 2 years, $43 \%(83)$ were between 2 and 4years, 16.6\%(32) were between 5 and 7 years,14\%(27) were 8 and 10years while $5.2 \%(18)$ had been in existence for more than 10 years. This implies that more than $50 \%$ of the businesses were less than 5 years in existence which is an indication that they were still in their development stage and would require support to survive. Analysis of the responses on nature of business of SMEs in the study revealed that $30.5 \%$ ( 59) were into service delivery, $19.2 \%$ ( 37) oil and gas, $17.1 \%$ ( 33) construction and $33.2 \%$ (64) were into ICT.

\subsection{SMEs Participation in Public Contract}

Results to the question that focused on determining the level of SMEs participation in public contract were presented in Table II. The result confirmed low level of SMEs participation in public contract in Lagos. It was observed that out of the 193 SMEs chief executives sampled only 67 of them representing $34.7 \%$ have ever participated in public contract in Lagos, while the rest 126 (52.3\%) respondents claimed they have never participated in public contract. Out of the 19 respondents who have ever participated in public contract $18(26.9 \%)$ claimed they have won contracts before, while 49(73.1\%) said they have never won.38.9\%(7) of the respondents attributed their winnings to low project cost, 16.7\%(3)attributed their winning to being the lowest bidder, while $11.1 \%(2)$ claimed it was as a result of the method of procurement adopted by the procuring entity. This is understandable because, the Public Procurement Act (PPA), 2007 allows procurement of minor value goods through request for quotations from at-least three un-related suppliers/ contractors. This allows SMEs to supply goods such as office equipment; stationeries and non-consultancy services.16.7\% (3) attributed their winnings to the fact that they are the lowest bidder.33.3\% (6) attributed their winnings to other factors such as sheer luck, offering of kick backs to procurement officials, sub-contracting, and joint venture. This further buttressed the fact that some bidders do engage in sharp practices with the help of procurement officials to win contract. 
Table I: Profile of the Respondent

\begin{tabular}{lll}
\hline Characteristic & Frequency & Percent \\
\hline Male & 131 & 67.9 \\
Female & 62 & 32.1 \\
Total & $\mathbf{1 9 3}$ & $\mathbf{1 0 0}$ \\
Highest Level of Education & & \\
Ph.D & 3 & 1.6 \\
Msc & 58 & 30 \\
Bsc/ HND & 126 & 65.3 \\
Diploma/Certificate & 6 & 3.1 \\
Total & $\mathbf{1 9 3}$ & $\mathbf{1 0 0}$ \\
Years in Business & & \\
Less than 2 years & 41 & 21.2 \\
Btw 2 and 4 years & 83 & 43 \\
Btw 5 and 7 years & 32 & 16.6 \\
Btw 8 and 10years & 27 & 14 \\
Above 10 years & 10 & 5.2 \\
Total & $\mathbf{1 9 3}$ & $\mathbf{1 0 0}$ \\
Nature of Business & & \\
Service & 59 & 30.5 \\
Construction & 33 & 17.1 \\
Oil and Gas & 37 & 19.2 \\
ICT & 64 & 33.2 \\
Total & $\mathbf{1 9 3}$ & $\mathbf{1 0 0}$ \\
\hline
\end{tabular}

Table II: SMEs Participation in Public Contract

\begin{tabular}{lll}
\hline Characteristic & Frequency & Percentage \\
\hline Ever Participated in Public Contract & & \\
Yes & 67 & 34.7 \\
No & 126 & 52.3 \\
Total & $\mathbf{1 9 3}$ & $\mathbf{1 0 0}$ \\
Ever won contract & & \\
Yes & 18 & 26.9 \\
No & 49 & 73.1 \\
Total & $\mathbf{6 7}$ & $\mathbf{1 0 0}$ \\
Reason for winning & & \\
Method of procurement adopted & 2 & 11.1 \\
Lowest bidder & 3 & 16.7 \\
Low contract cost & 7 & 38.9 \\
Others & 6 & 33.3 \\
Total & $\mathbf{1 8}$ & $\mathbf{1 0 0}$ \\
\hline
\end{tabular}

\subsection{Factors responsible for SMEs Low-Participation in Public Contract}

The mean and standard deviation of the 8 factors responsible for SME slow-participation in public contract in Lagos, Nigeria is presented in Table III. The computed mean score revealed that perceived lack of transparency in the public procurement proceeding ranked $1^{\text {st }}$ among the factors responsible for SMEs lack of interest in public contract in Lagos with a mean score of 4.30. The finding support the claim of Kaspar and Pudderphatt (2012) who submitted that one of the ways for government to assist SMEs in achieving their full potential is through their public procurement system. However, SMEs' entry into this potentially lucrative market is often hindered by challenges such as corruption, red-tape and lack of transparency. Transparency is a hallmark of good and sound public procurement which establishes and then maintain rules and procedures that are accessible and unambiguous (Bureau of Public Procurement, 2016).Procurement processes starting from the pre-bid to the post bid stage must not only be fair but must be seen to be fair. Situations where rules are changed in the middle of the game to favour "preferred bidder" and where information relating to selection, evaluation and award criteria are not clearly stated and made available to 'all bidders' put to test public confidence in public contract. Potential suppliers to the government are likely to compete only when they are confident that they have been provided with all necessary information and that their offers will be evaluated on the basis of objectives criteria in a non-discriminatory way and that decision of the procurement entity can be challenged before an independent body (United Nations Office on Drugs and Crime, 2013). 
In the $2^{\text {nd }}$ position is a disproportionate eligibility criterion with a mean score of 4.28 . This finding confirms the claim of Morrissey and Pittaway (2006) who averred that disproportionate qualification criteria and delayed payment are factors preventing SMEs participation in public contract. The insistence by some procuring entities on eligibility criteria such as evidence of registration of company with Corporate Affairs Commission, Annual turn-over, current PENSION certificate, Evidence of Industrial Training Fund, High profile professionals, relevant job done amongst others could be very daunting for growing SMEs.

Ranked $3^{\text {rd }}$ is the burdensome nature of public tenders. Public procurement involves lots of documentations, verification and evaluation processes. Meanwhile procurement activities are less cumbersome in the private sector which makes it more convenient for SMEs to buy from them. Processes involved in bidding are unnecessarily complex as it requires excessive documentation requirement which often time dissuade SMEs from participating in public contract.

In the $4^{\text {th }}$ position is delay /unfavorable terms of payment. This is understandable because, The PPA, 2007 allows a mobilization fee of not more than $15 \%$ of the contract sum on presentation of bank guarantee. Contract Payment are also made in milestones or measured work while some part of the money could be retain as retention fee to cover liability period which are usually not less than six months depending on the duration of the project completion.

In the $5^{\text {th }}$ position is the unethical behaviour of procurement officials with a mean score of 4.02. Unethical behaviour such as demanding for bribes from contractor, unfair treatment, disclosing confidential information while procurement proceedings is still in progress are serious challenges militating against efficient public procurement management in Nigeria. This finding is in agreement with the findings of Nkonge (2013) who revealed that ethical aspect hinders the SMEs from participating in tendering due to in-transparency in the process. This prevents active participation of SMEs in public tenders.

Bias evaluation /award criterion was ranked $6^{\text {th }}$ with a mean score 3.84. Most solicitation document for tenders does not include award criteria even when PPA clearly allows for it. The use of lowest evaluated responsive bid as criteria for award is also an issue for SMEs. Experts have advocated for 'most economic advantage tender' which brings about innovation and value for money. This would support SMEs chances of winning bids due to their innovative tendencies.

In the $7^{\text {th }}$ position is complex contract management with a mean score of 3.72 . Contract management in the public sector is more demanding. It starts right from the point of award to project hand-over. Contractors are expected to sign contract agreement, do stamp duty of the agreement which is at a fixed percentage of the contract sum, site meetings which often time requires feeding, monitoring and un-scheduled /scheduled inspection.

The least ranked factor is multiple deductions with a mean score of 3.67. Some respondents revealed during interviews that out of the little profits made on contracts, they are expected to pay for some levies such as endowment fund. According to them, all these taxes are deducted at source. They claimed this practice discourage them from participating in public contract.

Table III: Factors responsible for SMEs Low-Participation in Public Contract

\begin{tabular}{llll}
\hline Factors responsible for SMEs low participation in Public contract & Mean & Stand. Dev. & Ranking \\
\hline Disproportionate eligibility criteria & 4.28 & 0.91 & $2 \mathrm{nd}$ \\
Burdensome nature of public procurement & 4.20 & 0.96 & $3^{\text {rd }}$ \\
Multiple taxation & 3.82 & 1.25 & 7 th \\
Late / Unfavourable payment terms & 4.12 & 0.99 & $4^{\text {th }}$ \\
Perceived lack of transparency & 4.30 & 1.01 & $1^{\text {st }}$ \\
Unethical behaviour of procurement officials & 4.02 & 1.12 & $5^{\text {th }}$ \\
Bias evaluation/award criteria & 3.84 & 1.26 & 6 th \\
Complex contract management & 3.72 & 1.28 & 8 th \\
\hline
\end{tabular}

\section{Conclusion}

This study identified and ranked the factors responsible for SMEs low-participation in public contract despite the inherent benefits derivable from selling to government. The study revealed that lack of transparency in the conduct of public tendering is the foremost reason why some SMEs would rather choose to buy from the private sector and not participate in public contract in spite of the Public Procurement Act, 2007 which proscribe ambiguity in public contract are not sometimes adhered to by government MDAs. The effect of this is low participation of SMEs in public contract since they do not have confidence in the process. It was also revealed through the study that SMEs have issues with disproportionate eligibility criteria, bias award criteria, payment terms as well as complex contract management system adopted by government MDAs in public contract.

\section{Recommendations}

Based on the findings of this study, the following recommendations were made: 
i. There is need for the Bureau of Public Procurement (BPP) to continue to vigorously carry out its oversight function of ensuring that MDAs comply with all provisions of the PPA, 2007 as it relates to transparency and competition in public contract and that professional ethics are adhered to. This can be achieved by carrying out periodic audit of MDAs procurement exercise as well as organizing trainings for procurement professionals in MDAs. Any herring public servant who engages in unethical behaviour capable of undermining the integrity of public procurement process should be adequately sanctioned in line with the provisions of the PPA, 2007.

ii. There is need to simplify tendering processes and reduce administrative burden in public procurement. Procurement process should involve minimal paper work. Requesting for documents that are an integral part of the evaluation of tenders will go a long way to reduce administrative burden associated with public procurement. Also, the country needs to embrace e-procurement which involves the use of online electronic technologies to carry out procurement process. This will help to reduce paper work, cost and ensures SMEs easy and timely access to information as well as reduces corrupt practices such as bribery since it limits direct contact between the purchasing entity and the supplier.

iii. There is also need for a review of the existing procurement legal framework and policies to cater for SMEs. Beyond domestic preference which is only applicable in ICB, there should be a sort of competitive advantage for SMEs when tendering for contract under National Competitive Bidding (NCB).Nigeria government can take a cue from countries such like China where the government set aside at least $30 \%$ of annual budgets for SME procurement, with not less than $60 \%$ of this amount reserved for small and micro enterprises to boost SME participation in public contract. This will help to make money available for SMEs to finance contract when awarded instead of the $15 \%$ mobilization fee provided for in the PPA.

\section{References}

Akenroye, T., \& Aju, O. (2013). Barriers to small and medium enterprises participation in public procurement in Nigeria: Some preliminary results. Inderscience Enterprises Ltd. pp 313-328.

Bureau of Public Procurement (2016). Public Procurement Procedure Manual (Nigeria) pg 5

Ebig, M., \&Ghas, A.H. (2016).Considering small and medium sized supplier in public procurement: The case of the German Defence Sector. Springer International publishing Switzerland, pp. 19-33.

Ekanayake, L.L., \& Ofori,G.(2004). Building waste assessment score: Design-based tool. Building and Environment, 39,851-861.

Fee, R., Erridge, A., \& Hennigan, S. (2002). Small and medium enterprises and government purchasing in Northern Ireland: Problems and opportunities. European Business Review, 14(5), 660-679.

Flynn, A., \& Davis, P. (2016).Investigating the effect of tendering capabilities on SME activity and performance in public contract competitions. International Small Business Journal, 1-21.

George,D., \&Mallery, P.(2003). SPSS for windows step by step: A simple guide and reference. 11.0 update $\left(4^{\text {the }}\right.$ ed). Boston: Allyn \& Bacon.

Georghious, L., Edler, J., Uyarra, L. (2014). Policy instruments for public procurement of innovation: Choice, design and assessment. Technological Forecasting and Social change, 86, 1-12.

Huka, H.A. (2016). Contribution of public procurement to the success of small and medium enterprises: A case of SMEs in Moshi Municipality. The International Journal of Business and Management, 4(3), 146-152.

Ihua, U.B. (2010).Local content policy and SMEs sector promotion: the Nigerian oil industry experience. International Journal of Business and Management, 5(5), 3-12.

Loader, K. (2005).Supporting small and medium enterprises through government purchasing activity. The International Journal of Entrepreneurship and Innovation, 6(1) 17-26.

MacManus, S.(1991). Why businesses are reluctant to sell to government? Public Administration Review,51(4), 328-344.

Macpherson, A., \& Holt.R. (2007). Knowledge learning and small -firm growth: a systematic review of evidence. In Akenroye, T., \&Oluseyi, A. (2013).Barriers to SMEs participation in public procurement in Nigeria: Some preliminary results. Inderscience Enterprises Ltd. pp 313-328.

Morrisey, J., \&Pittaway, L. (2006). Buyer-supplier relationships in small firms: the use of social factors to manage relationships. International Small Business Journal, 24(3), 257-267.

Nkonge, B.K. (2013). Challenges faced by Small and medium Enterprise suppliers when bidding for tenders. A case of Thika District. International Journal of Academic Research in Business and Social Sciences, 6(4), $12-19$.

Obanda, W. (2011).Small and medium enterprises and public procurement contract in developing countries. Kampala: Longhorn publishers.

Peprah, J.A., Mensah, A.O., \&Akosah, N.B. (2016). Small and medium sized Enterprises (SMEs) accessibility to 
public procurement: SMEs Entity perspective in Ghana. European Journal of Business and Social Sciences, 4(11), 25-43.

Purchase, S., Goh, T., \& Dooley K. (2009). Supplier perceived value: Differences between business to business and business to government relationships. Journal of Purchasing and Supply Management, 15(1), 3-11.

Small and Medium Enterprises Development Agency of Nigeria and National Bureau of Statistics (2013) Collaborative survey: Small and Medium Enterprises in Nigeria. Abuja: FGN.

Tumkella, K. (2003). The challenge of globalization and SME sector in Nigeria: repositioning through technology and innovation. Paper presented at the National Summit on SMIESIS organized by the Bankers Committee and Lagos Chambers of Commerce and Industry (LCCI), Lagos, 10 June 2003.

United Nations Office on Drugs and Crime (2013).Guidebook on anti-corruption in public procurement and the management of public finances. Good practices in ensuring compliance with article 9 of the United Nations Convention against Corruptions.

World Bank (1995). Guidelines: Procurement under IBRD and IDA Credits, World Bank Washington D.C.

World Bank (2003).Public Procurement Act of Ghana - Country Procurement Assessment Report. Washington D.C. The World Bank Report.

Zheng, J., Walker, H., \& Harland, C. (2006).The role of SME in public procurement. A review of literature and research agenda. 